\title{
Long-Term Outcomes and Prognosis of Transrectal High-Intensity Focused Ultrasound Therapy for Patients with Localized Prostate Cancer-Therapy after Recurrence and Predictive Factors
}

\author{
Mutsuo Hayashi ${ }^{*}$, Tetsutaro Hayashi², Kiyotaka Oka1, Keisuke Goto², Shunsuke Shinmei², \\ Yoji Inoue $^{3}$, Katsumi Inoue ${ }^{1}$
}

${ }^{1}$ Department of Urology, Takanobashi Central Hospital, Hiroshima, Japan

${ }^{2}$ Department of Urology, Hiroshima University Hospital, Hiroshima, Japan

${ }^{3}$ Department of Urology, Mazda Hospital, Hiroshima, Japan

Email: ^m6-hayashi@hi.enjoy.ne.jp

How to cite this paper: Hayashi, M., Hayashi, T., Oka, K., Goto, K., Shinmei, S., Inoue, Y. and Inoue, K. (2017) Long-Term Outcomes and Prognosis of Transrectal HighIntensity Focused Ultrasound Therapy for Patients with Localized Prostate CancerTherapy after Recurrence and Predictive Factors. Open Journal of Urology, 7, 87-102. https://doi.org/10.4236/oju.2017.76012

Received: May 9, 2017

Accepted: June 26, 2017

Published: June 29, 2017

Copyright $\odot 2017$ by authors and Scientific Research Publishing Inc. This work is licensed under the Creative Commons Attribution International License (CC BY 4.0).

http://creativecommons.org/licenses/by/4.0/

\begin{abstract}
Objectives: To evaluate the outcomes and prognosis of high-intensity focused ultrasound (HIFU) therapy for patients with localized prostate cancer, and identify suitable candidates for this therapy by investigating the predictive factors. Methods: The 224 patients (low 54, intermediate 111 and high-risk patients 59) with T1-2 stage were treated using the Sonablate device and followed for over 12 months after treatment. Recurrence was determined based on histological findings, prostate-specific antigen (PSA) failure and local or distant metastasis. The factors which are predicting variables with potential effects were investigated by Kaplan-Meier and multivariate analysis. Results: A total of 255 treatment sessions (193 with one, 31 with two) were performed. No patients died of prostate cancer, but 15 died of other causes and 14 patients were lost during follow-up. The 7-year recurrence-free survival (RFS) rates in all patients were $75 \%$, and 5-year RFS rates were $98 \%, 84 \%$ and $59 \%$ in the low, intermediate and high-risk patients respectively. In the 216 patients who underwent histological examination at 6 months or later after HIFU, 25 (12\%) were positive. In 77 patients with recurrence after first-HIFU, the second treatments were hormonal therapy and HIFU. Of the 31 patients who underwent a second HIFU, the 5-year RFS rates were $64 \%$, and 5-year RFS rates were $100 \%, 74 \%$ and $33 \%$ in the low, intermediate and high-risk patients. The significant predictor for recurrence was risk-group, T-stage (T1 vs T2), Gleason score ( $\leq 3+4$ and $\geq 4+3$ ), pretreatment PSA ( $<10$ vs $\geq 10 \mathrm{ng} / \mathrm{ml}$ ) and nadir PSA ( $<0.1 \mathrm{vs} \geq 0.1 \mathrm{ng} / \mathrm{ml})$. In 111 patients with intermediate-risk,
\end{abstract}


T-stage and nadir PSA were significantly associated with outcomes. Conclusions: Prognosis of HIFU for Patients with localized prostate cancer was good, and the low and intermediate-risk patients with T1-staging are suitable indications for HIFU. Effective predictors for outcomes were risk-group, T-stage, Gleason score, pretreatment PSA and nadir PSA.

\section{Keywords}

High-Intensity Focused Ultrasound, Localized Prostate Cancer, Treatment Outcomes and Prognosis, Recurrence-Free Survival, Treatment Predictor

\section{Introduction}

In recent years, with the high incidence of prostate cancer worldwide, the proportion of early stage prostate cancer has increased. PSA testing and higher male life expectancy have led to increased diagnosis of localized prostate cancer. Several treatment options for this disease are available including the two standard treatment options, radical prostatectomy through open or laparoscopic surgery, and radiation therapy. The morbidity associated with these radical treatments is significant, although the treatment outcomes is good, and the improvement of the procedure and the devices have reduced the associated side effects in recent years [1] [2] [3] [4] [5]. Recently, many alternative and less invasive treatments have been developed for localized prostate cancer [6] [7]. In 1995, Madersbacher et al. [8] reported the effect of high intensity focused ultrasound (HIFU) in an experimental study of 10 patients with prostate cancer. HIFU is a noninvasive technique for thermal ablation of tissue that can induce complete coagulation necrosis of a targeted tumor without requiring surgical exposure or insertion of invasive instruments. Besides, Gelet et al. reported that transrectal HIFU prostate ablation was an effective therapeutic alternative for patients with localized prostatic adenocarcinoma and this treatment had further major advantages [9]. Since May 2003, we have treated patients with localized prostate cancer who were not suitable for, or did not desire radical prostatectomy or radiotherapy, and we have reported the efficacy and safety of HIFU ablation for patients with prostate cancer [10] [11]. According to these experiences, HIFU therapy has the advantages of fewer complications, simplicity of the procedure, shorter treatment times, and the potential for a repeat treatment [11]. Our results suggest that HIFU is an effective treatment in patients with low and intermediate-risk localized prostate cancer, but it is not effective for high-risk patients. Here we retrospectively examine the long-term outcomes of the first and second HIFU therapies, prognosis and RFS, and consider which patients are suitable for this treatment.

\section{Methods}

From May 2003 to February 2017, we have administered transrectal HIFU therapy to patients with clinical stage T1 or T2 N0M0 prostate cancer using the So- 
nablate HIFU devices (Sonacare Medical, Inc., Indianapolis, IN, USA). We used the Sonablate $500^{\mathrm{TM}}$ since May 2003 and the update Sonablate $500^{\mathrm{TM}}$ version 4 since April 2006. The disease was staged with histological findings, digital rectal examinations, and imaging examinations such as CT, MRI and bone scintigraphy when deemed beneficial, and then classified by D'Amico risk group [12]. Of these 242 patients who underwent HIFU, 224 patients were followed up for more than 12 months after their last HIFU treatment. For their follow-up examinations, a sextant prostate biopsy and MRI were conducted at 6 months and additional follow-up periods when deemed necessary. The PSA was assayed every 3 months after treatment.

None of the patients received adjuvant therapy during the follow-up period. Recurrence free outcome of the HIFU treatment was determined based on negative histological findings on follow-up biopsy, negative biochemical tests using the ASTRO definition in Phoenix [13] (PSA nadir $<+2 \mathrm{ng} / \mathrm{ml}$ ) and no local nor distant metastasis. Actual recurrence-free survival (RFS) rates were calculated according to the Kaplan-Meier curves, and the log-rank test was used to compare the results between the variable groups, such as age ( $<70 \mathrm{vs} \geq 70)$, pretreatment prostate volume ( $<25 \mathrm{vs} \geq 25 \mathrm{ml}$ ), risk-group, T-stage (T1 vs T2), Gleason score ( $\leq 6$ vs $3+4$ vs $4+3$ vs $\geq 8$ ), pretreatment PSA ( $<10$ vs $\geq 10 \mathrm{ng} / \mathrm{ml}$ ), nadir PSA ( $<0.1 \mathrm{vs} \geq 0.1 \mathrm{ng} / \mathrm{ml}$ ), $\%$ of positive cores $(<40 \%$ vs $\geq 40 \%$ ), ADT before HIFU ( $<$ for 3 vs $\geq 3$ months) and HIFU device (Sonablate 500 vs version 4 ). To estimate the prognostic factors, these factors without risk group were calculated by multivariate Cox proportional Hazards regression model. P-value of $<0.05$ was considered to indicate statistically significant differences. These were calculated on the total and intermediate-risk patients after first HIFU treatment.

We fully informed all patients who received the diagnosis of localized (stage $\mathrm{T} 1$ - T2) prostate cancer of their different treatment options and selected the patients who were not suitable candidates for radical surgery and did not desire radical surgery and radiotherapy. All patients who wanted HIFU therapy provided informed consent for the HIFU treatment and accepted self-pay burden for an uninsured therapy in Japan, and the institutional review board for Takanobashi Central Hospital approved these studies.

\section{Results}

1) Overall outcomes of the treatment with HIFU for localized prostate cancer

This series included 224 patients who were followed-up for more than 12 months after their last HIFU therapy. The patients had a mean age of 68 years old, a mean prostate volume before HIFU of $23.5 \mathrm{ml}$ and a mean PSA level at diagnosis of $9.7 \mathrm{ng} / \mathrm{ml}$. The percentage of these patients classified by initial PSA level, Gleason scores and clinical T-stages are shown in Table 1 . The low, intermediate and high-risk groups included 54, 111 and 59 patients, respectively. Fifty-nine patients ( 5 low, 23 intermediate, and 31 high risk group) received ADT for more than 3 months before HIFU and 28 patients (9 low, 16 intermediate, and 3 high-risk groups) underwent TUR-P for the treatment of benign prostate 
Table 1. Characteristics of 224 patients with localized prostate cancer followed-up for over 12 months after latest HIFU.

\begin{tabular}{|c|c|c|c|c|}
\hline & & Mean \pm SD & No. pts. & $(\%)$ \\
\hline Age (yrs.) & & $68.3 \pm 6.7$ & & \\
\hline Prostate volume (mL) & & $23.5 \pm 7.8$ & & \\
\hline \multirow[t]{4}{*}{ Initial PSA (ng/mL) } & & $9.7 \pm 9.7$ & & \\
\hline & $<10$ & & 154 & 69 \\
\hline & $10-<20$ & & 60 & 27 \\
\hline & $\geq 20$ & & 10 & 4 \\
\hline \multirow[t]{3}{*}{ Gleason score } & $\leq 6$ & & 69 & 31 \\
\hline & 7 & & 105 & 47 \\
\hline & $\geq 8$ & & 50 & 22 \\
\hline \multirow[t]{5}{*}{ Clinical diagnosis } & $\mathrm{T} 1 \mathrm{~b}$ & & 13 & 6 \\
\hline & T1c & & 105 & 47 \\
\hline & T2a & & 76 & 34 \\
\hline & $\mathrm{T} 2 \mathrm{~b}$ & & 23 & 10 \\
\hline & $\mathrm{T} 2 \mathrm{c}$ & & 7 & 3 \\
\hline \multirow[t]{3}{*}{ Risk group } & \multicolumn{2}{|c|}{ Low } & 54 & 24 \\
\hline & \multicolumn{2}{|c|}{ Intermediate } & 111 & 50 \\
\hline & \multicolumn{2}{|c|}{ High } & 59 & 26 \\
\hline \multirow[t]{2}{*}{ Treatment before HIFU } & \multicolumn{2}{|c|}{$\mathrm{ADT} \geq 3$ months } & 59 & 26 \\
\hline & \multicolumn{2}{|l|}{ TUR-P } & 28 & 13 \\
\hline
\end{tabular}

SD: standard deviation, ADT: androgen deprivation therapy, TUR-P: transurethral resection of prostate.

hypertrophy (26 cases) and to reduce prostate volume (2 cases).

In this series, the prostate cancer was treated in 193 patients with one procedure, and 31 patients had two procedures of HIFU. In total, 255 HIFU procedures were performed (an average of 1.14 sessions per patient). HIFU treatment was repeated due to PSA failure in 31 cases and 11 cases had positive biopsies. All treatments except one (caudal anesthesia) were conducted under spinal anesthesia. Six of the 224 cases with first-time HIFU were treated with unilateral HIFU sonication, and 5 of 31 cases with a second HIFU were treated with focal HIFU sonication. The mean operation and HIFU exposure times were $146 \mathrm{~min}$. (range 60 - 255) and $88 \mathrm{~min}$. (35 - 185) respectively. The mean hospital stay and urethral catheterization period were 4 days and 14 postoperative days. There were no intraoperative adverse effects.

The mean follow-up period after the last HIFU treatment was 84 months (range 12 - 163). The mean nadir PSA in all cases was $0.268 \mathrm{ng} / \mathrm{ml}(<0.008-$ 2.81 ) and was reached in a mean 2.6 months ( 1 - 12). Nadir PSA $<0.1 \mathrm{ng} / \mathrm{ml}$ was noted in $54 \%$ of cases. The mean nadir PSA in 165 cases without ADT was 0.305 $\mathrm{ng} / \mathrm{ml}$ and was reached in a mean 3.1 months $(1-6)$. Of the 216 patients who underwent a histological examination at 6 months after HIFU, 8 (3.7\%) had positive specimens with an additional 2 specimens identified during TUR proce- 
dures. Furthermore, 17 patients (14 through prostate biopsies and 3 by TURbladder neck because of difficulty in voiding) had a positive specimen during the follow-up period. As for the prognosis in all patients, although no patients died of prostate cancer in any of the cases, 15 died of another cause (8 from cardiovascular disease, 4 from cancer of another organ, 2 from respiratory disease and 1 from a traffic accident), and 14 patients were lost during follow-up (Table 2).

The 7-year cancer specific survival (CSS) and over-all survival (OAS) rates in all patients was $100 \%$ and $94 \%$, respectively. The 5,7 , and 10 -year RFS rates using ASTRO definition in all patients were $81 \%, 75 \%$ and $66 \%$. The 7 -year RFS rates were $94 \%, 76 \%$ and $54 \%$ in the low, intermediate and high-risk groups, respectively. There was a significant difference between the low and intermediate-risk group $(\mathrm{P}=0.006)$, between the low and high-risk group $(\mathrm{P}<0.001)$, and between the intermediate and high-risk group $(\mathrm{P}=0.002)$ (Figure 1).

2) Outcomes of recurrent cases after first HIFU

Of the 224 patients who underwent first-time HIFU, 77 (34\%) cases (10, 35, and 32 in the low, intermediate and high-risk groups) recurred (Table 3). Of the 77 patients who underwent a histological examination at 6 months after HIFU, 3 (6\%) of the 52 patients with low-risk, 11 (10\%) of 107 patients with intermediate-risk and 12 (21\%) of 57 patients with high-risk had positive specimens. Regarding patients' treatment after recurrence, no patients chose prostatectomy, 41 had hormonal therapy (ADT), 31 were retreated with HIFU, 4 received radiotherapy, 1 underwent castration, 5 chose no therapy and 2 were lost in follow-up. On the all recurrent patients, there were no patients died of prostate cancer, 4 died of another cause and 11 were lost follow.

Table 2. PSA, histological results and prognosis of HIFU therapy in 224 patients.

\begin{tabular}{|c|c|c|c|c|c|c|}
\hline Nadir PSA: & Mean & & Range & & No. pts. & $\%$ \\
\hline & 0.268 & & $<0.008-2.81$ & & & \\
\hline & & & & $<0.1$ & 120 & 53.6 \\
\hline & & & & $0.1-1$ & 91 & 40.6 \\
\hline & & & & $\geq 1$ & 13 & 5.8 \\
\hline \multirow[t]{4}{*}{ Histological finding; } & Positive pts./biopsy pts. & After HIFU & 6 months & 7 months & Total & $\%$ \\
\hline & Prostate biopsy & & $8 / 216$ & $14 / 25$ & $22 / 216$ & 10.2 \\
\hline & TUR biopsy & & $2 * / 6$ & $4 / 8$ & $4+2^{\star} / 14$ & 42.9 \\
\hline & Total & & $8 / 216$ & $18 / 33$ & $26 / 216$ & 12 \\
\hline \multirow[t]{7}{*}{ Prognosis: } & & No. pts. & & & & No. pts. \\
\hline & Lost follow & 14 & & & & \\
\hline & Died from prostate ca. & 0 & & & & \\
\hline & Died from another dis. & 15 & & Cause disease: & Cardiovascular dis. & 8 \\
\hline & & & & & Another cancerous dis. & 4 \\
\hline & & & & & Respiratory dis. & 2 \\
\hline & & & & & Traffic accident & 1 \\
\hline
\end{tabular}

Ca.: cancer, Dis.: disease, TUR: transurethral resection, *: overlap cases. 
(a)

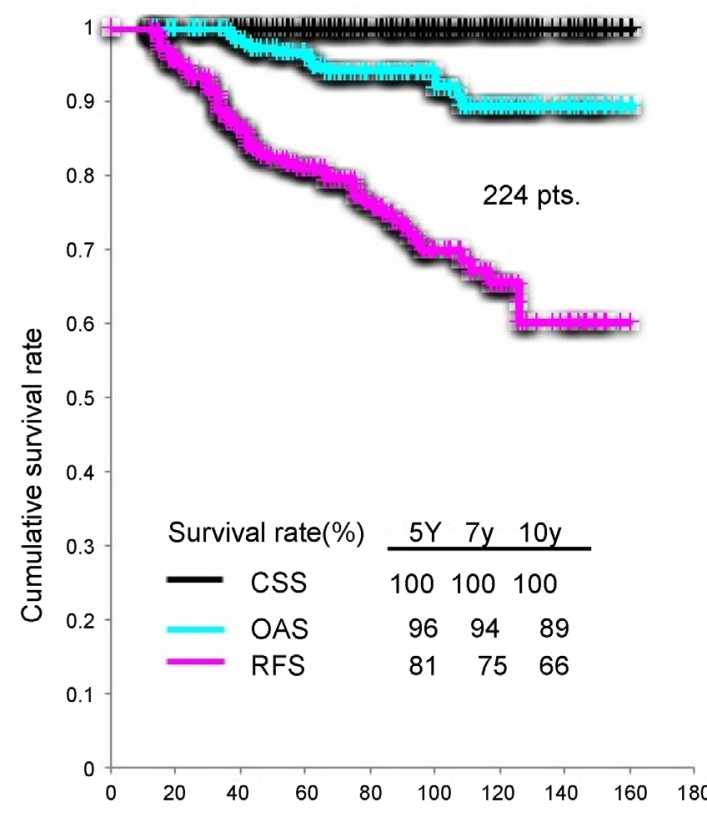

No. pts

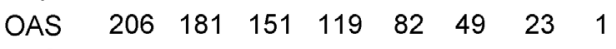

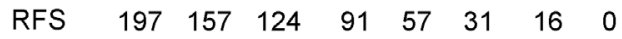

(b)

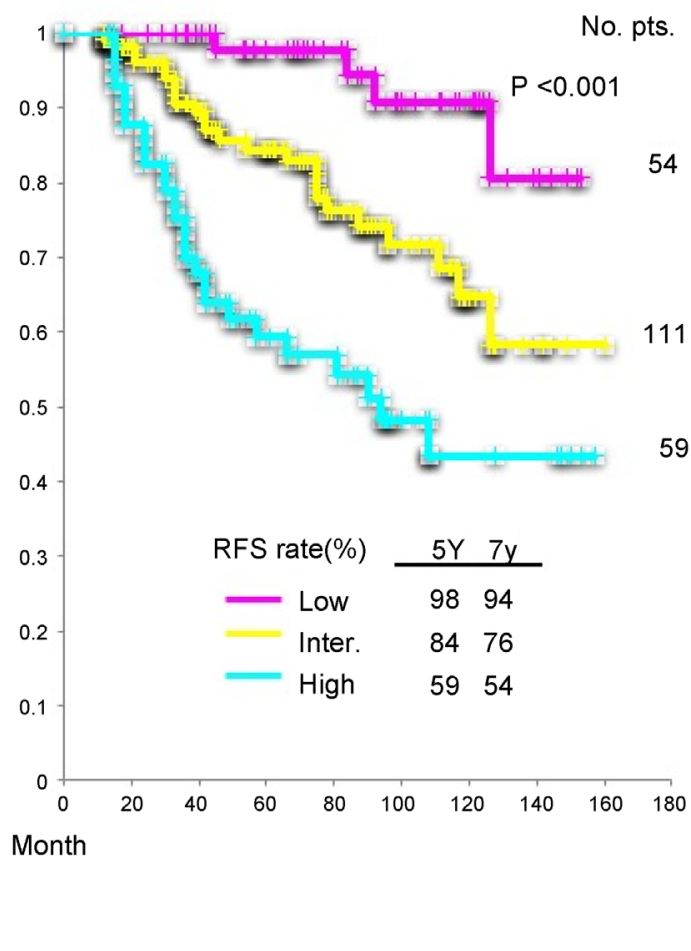

Figure 1. Kaplan-Meier curves of survival rates in 224 patients with localized prostate cancer following HIFU therapy: (a) Curves of cancer specific survival, overall survival and recurrence-free survival rates; (b) Curves of recurrence-free survival rates according to risk-groups. CSS: cancer specific survival, OAS: over all survival, RFS: recurrence-free survival, Inter.: intermediate.

Table 3. Recurrence of patients with first and second HIFU, and the treatments after recurrence.

\begin{tabular}{|c|c|c|c|c|c|c|}
\hline & Risk group & No. pts. & Recurrence pts. (\%) & Positive biopsy (\%) & Treatments after recurrence & No. pts. \\
\hline & Low & 54 & $10(19)$ & $3 / 52(6)$ & HIFU & 31 \\
\hline \multirow[t]{6}{*}{ First HIFU } & Intermediate & 111 & $35(32)$ & $11 / 107(10)$ & $\mathrm{ADT}$ & $41\left(3^{*}\right)$ \\
\hline & High & 59 & $32(54)$ & $12 / 57(21)$ & Radiotherapy & $4\left(3^{*}\right)$ \\
\hline & Total & 224 & $77(34)$ & $26 / 216(12)$ & Castration & $1^{*}$ \\
\hline & & & & & No treatment & 5 \\
\hline & & & & & Unknown & 2 \\
\hline & Low & 7 & $1(14)$ & $0 / 7(0)$ & Endocrine therapy & 8 \\
\hline \multirow[t]{3}{*}{ Second HIFU } & Intermediate & 13 & $2(15)$ & $0 / 11(0)$ & Radiotherapy & $1^{*}$ \\
\hline & High & 11 & $6(55)$ & $1 / 10(10)$ & Unknown & 1 \\
\hline & Total & 31 & $9(29)$ & $1 / 28(3)$ & & \\
\hline
\end{tabular}

*: overlap cases.

The median follow-up period after a second HIFU treatment was 62 months (range 13 - 148). Median nadir PSA in 31 cases after a second HIFU treatment was $0.246 \mathrm{ng} / \mathrm{ml}(0.007-1.26)$ and was reached in a median of 1 month (1 - 5). Of the 31 patients who underwent a second HIFU treatment, only one patient with high-risk cancer had a positive biopsy at 6 months after the second HIFU. The 5-year CSS and OAS rates in these 31 patients were $100 \%$ and $100 \%$, and the 
5 and 7 -year RFS rates were $64 \%$ and $51 \%$. The 5-year RFS rates were $100 \%, 74 \%$ and $33 \%$ in the low, intermediate and high-risk groups, respectively (Figure 2(a) and Figure 2(b)). After recurrence, 8 patients had ADT, 1 wanted radiotherapy

(a)

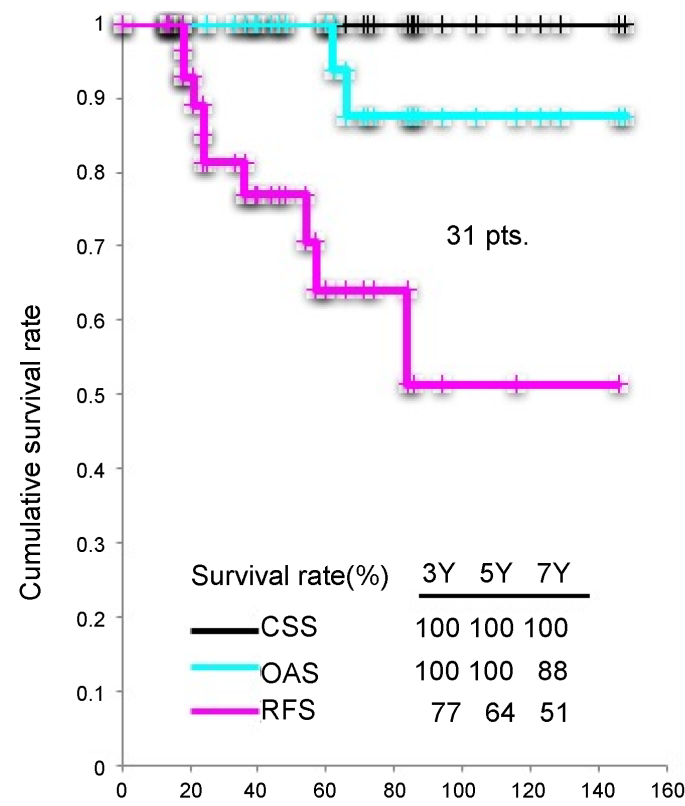

No. pts.

$\begin{array}{lllllllll}\text { OAS } & 26 & 21 & 16 & 11 & 6 & 4 & 2 & 2\end{array}$ $\begin{array}{lllllllll}\text { RFS } & 24 & 15 & 8 & 5 & 2 & 1 & 1 & 1\end{array}$ (b)

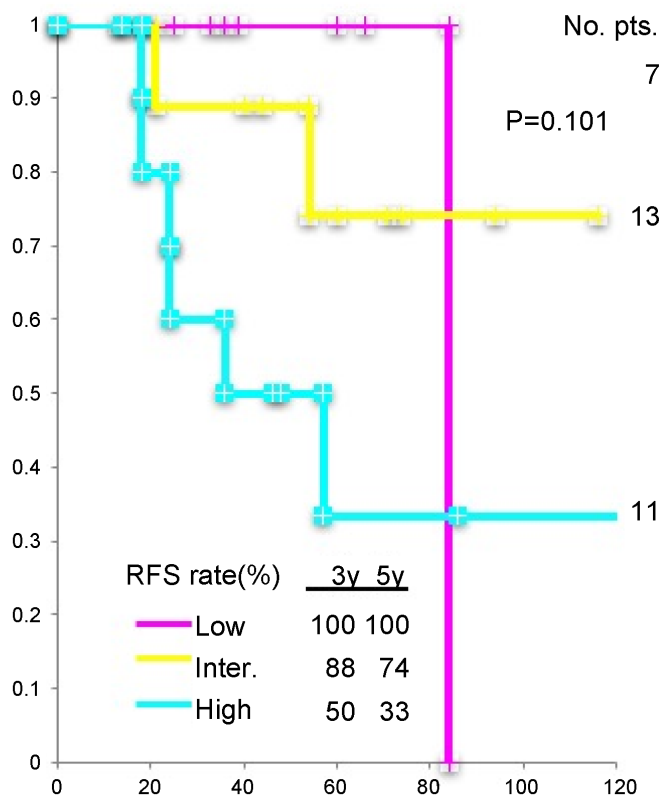

Month

(c)

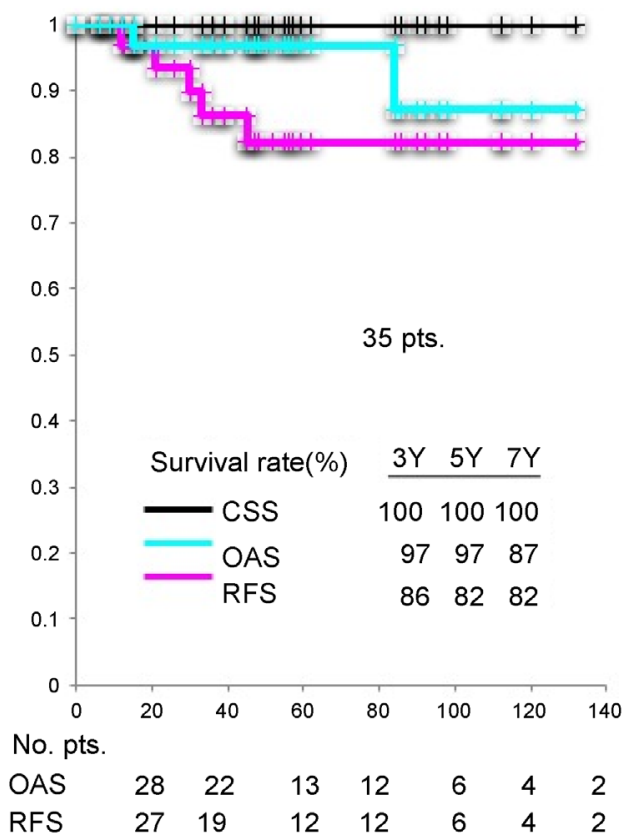

Figure 2. Kaplan-Meier curves of survival rates in recurrent patients with first HIFU therapy: (a) Cancer specific survival, overall survival and recurrence-free survival rates of 31 patients with second HIFU therapy; (b) Recurrence-free survival rates of same 31 patients according to risk-groups; (c) Cancer specific survival, overall survival and recurrence-free survival rates of 35 patients with ADT. 
and 1 has not decided yet (Table 3). All of recurrent patients were alive well now. And the 5-year CSS and OAS rates in 35 patients with only ADT after recurrence were $100 \%$ and $97 \%$, and the 5 and 7 -year RFS rates were $82 \%$ (Figure $2(c))$.

3) Predictive factors from RFS rates in all patients with first-time HIFU

The 5 and 7-year RFS rates of first time HIFU in all patients were $73 \%$ and $65 \%$. The 7 -year RFS rates were $84 \%, 66 \%$ and $46 \%$ in the low, intermediate and high-risk groups, respectively. There was a significant difference between the low and intermediate-risk group $(\mathrm{P}=0.027)$, between the low and high-risk group $(\mathrm{P}<0.001)$ and between the intermediate and high-risk group $(\mathrm{P}=0.005)$ (Figure 3).

The Kaplan-Meier curves of 10 variable factors of RFS after the first-HIFU treatment as determined by ASTRO definition are shown in Table 4. There was a significant difference in the risk-group $(\mathrm{P}<0.001)$, T-stage $(\mathrm{P}=0.003)$, Gleason score $(\mathrm{P}=0.003)$, pretreatment PSA $(\mathrm{P}<0.001)$, nadir PSA $(\mathrm{P}<0.001)$ and HIFU device $(P=0.049)$ factors, whereas age, prostate volume, $\%$ of positive core and ADT before HIFU showed little difference in Table 4 . There was a significant difference $(\mathrm{P}<0.001)$ between the Gleason 7 score group of $\leq 3+4$ and $\geq 4+3$. The multivariate analysis of variable factors with significant difference under Kaplan-Meier analysis is shown in Table 4 . These analyses revealed that there is a significant difference in the $\mathrm{T}$-stage $(\mathrm{P}=0.040)$, Gleason score $(\leq 6 \mathrm{vs} \geq 8 ; \mathrm{P}=$ $0.002)$, pretreatment PSA $(\mathrm{P}=0.022)$, nadir PSA $(\mathrm{P}<0.001)$ and HIFU device $(\mathrm{P}=$ $0.014)$.

4) Kaplan-Meier statistical analyses of factors affecting RFS rates in 111 intermediate-risk patients with first-time HIFU and in 31 patients with a secondHIFU (Table 5).

We examined 111 patients with intermediate-risk using the same analyses. By Kaplan-Meier analysis, clinical T-stage and nadir PSA were significantly associated with prognosis. On 5-year RFS rates, there was a clear difference between T1 and $\mathrm{T} 2$ of T-stage and $\leq 3+4$ and $\geq 4+3$ of Gleason scores. We examined the 31 second-time HIFU patients using Kaplan-Meier analysis. Nadir PSA $(\mathrm{P}=0.018)$ was significantly associated with prognosis. Risk-group (low vs high) and Gleason score ( $\leq 6$ vs $\geq 8$ ) showed a slightly significant association with prognosis.

\section{Discussion}

Since the first clinical application of HIFU for treatment of localized prostate cancer are used by Madersbacher et al. [8]. (Using the Sonablate 200), several investigations of HIFU therapy using Ablatherm or Sonablate systems have been reported for patients with this disease [14] [15] [16]. We have performed transrectal HIFU treatment for localized prostate cancer using the Sonablate device since May 2003. Although all cases were not treated with whole-gland ablation, we analyzed all patients on the same basis because there were only 11 patients with unilateral and focal HIFU. There have been favorable results from the use of focal therapy recently reported [17] [18]. We will report on our experience 
(a) Risk group

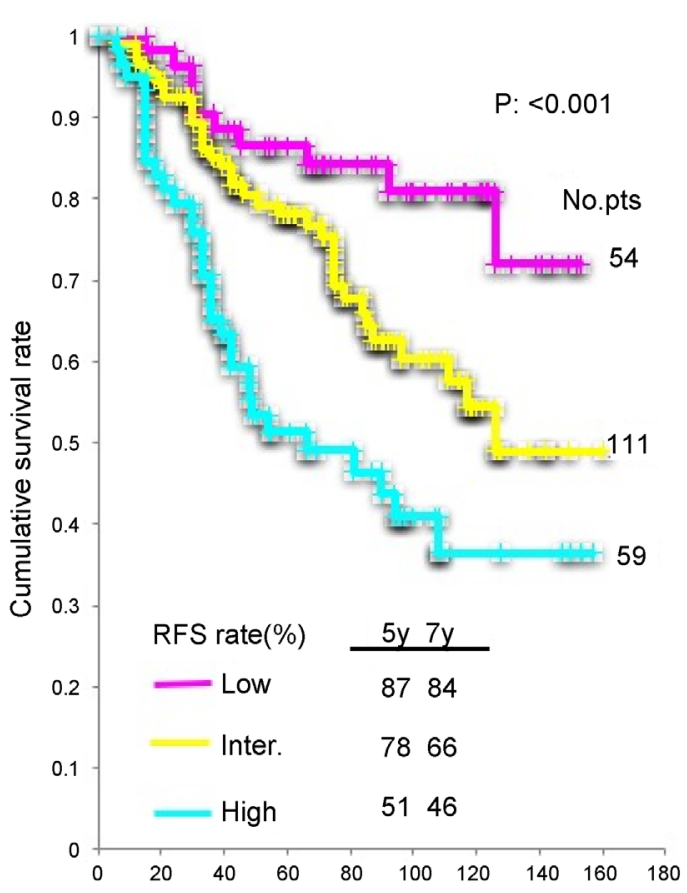

(b) Gleason score

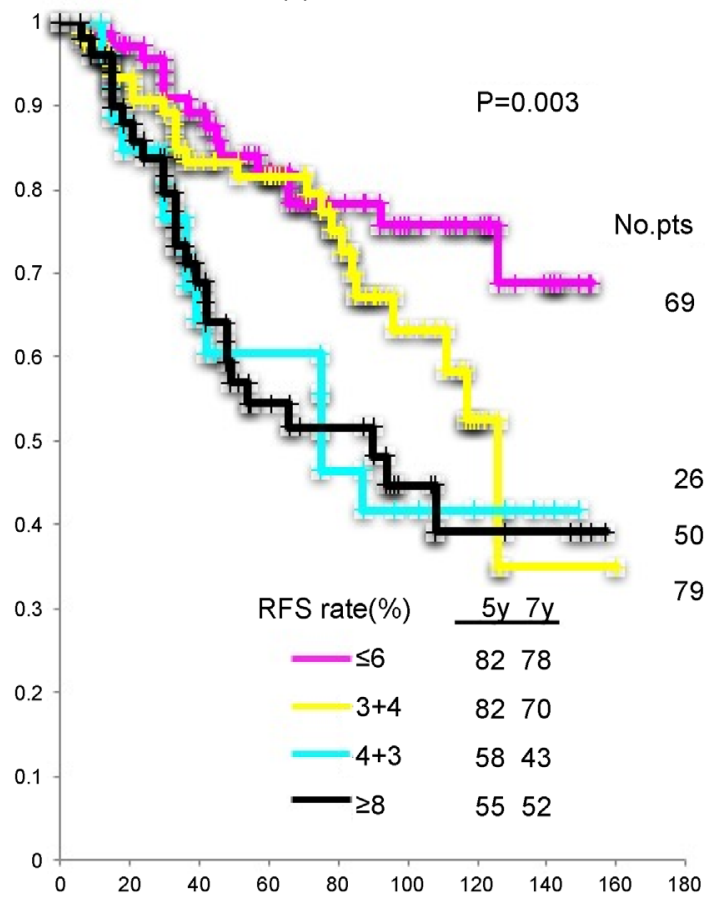

(c) T-stage

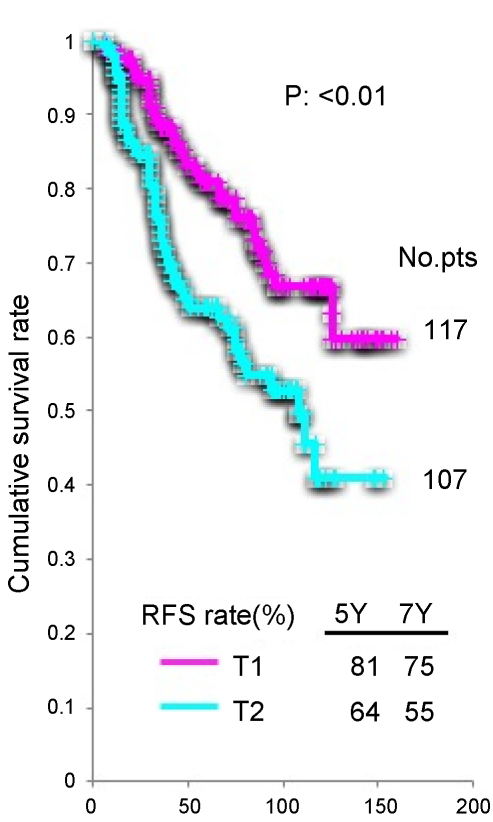

Months
(d) Initial PSA

(d) Initial PSA

(e) Nadir PSA
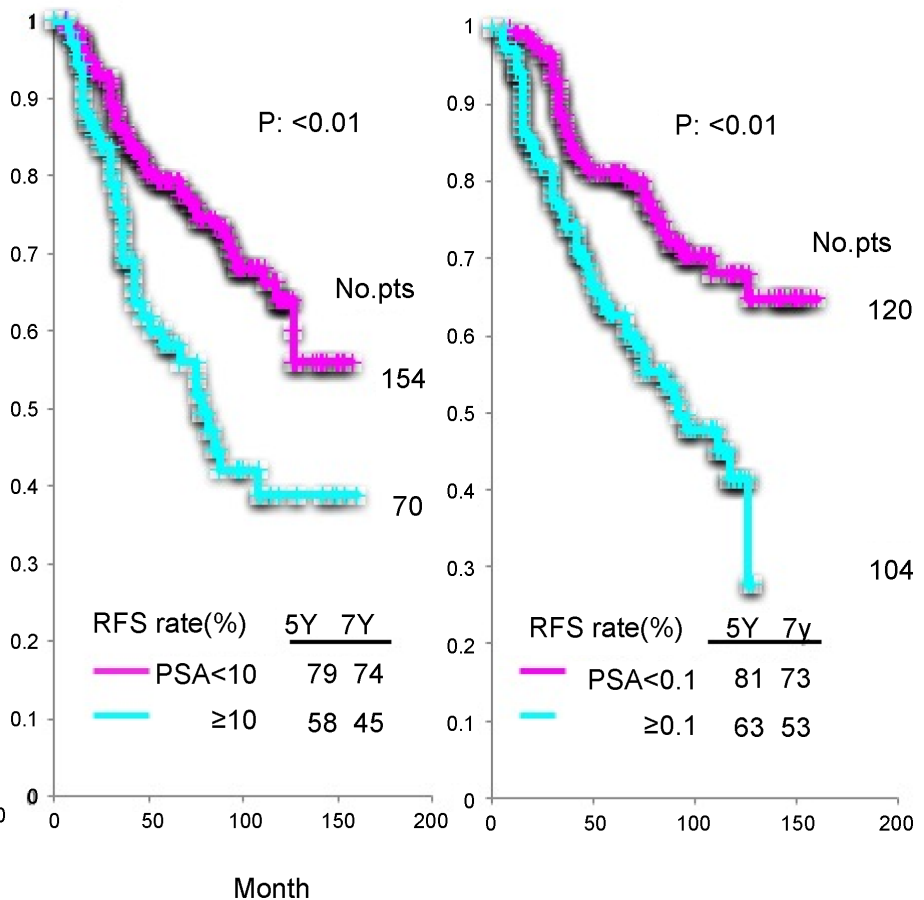

Figure 3. Recurrence-free survival curves following first HIFU therapy: (a) Risk-group; (b) Gleason score; (c) Clinical T-stage; (d) Initial PSA level; (e) Nadir PSA level.

with focal HIFU therapy in future.

Seven-year CSS and OAS in all patients were $100 \%$ and $94 \%$, and no patients died of prostate cancer even in recurrent cases. Although both survival rates will diminish slightly if some of the 14 patients lost during follow-up are included in 
Table 4. Kaplan-Meier and multivariate statistical analyses of variable factors affecting recurrence-free survival in all patients with first HIFU.

\begin{tabular}{|c|c|c|c|c|c|c|c|c|c|}
\hline \multirow[b]{2}{*}{ Variables } & & \multicolumn{4}{|c|}{ Kaplan-Meier } & \multicolumn{4}{|c|}{ Multivariate } \\
\hline & & No.pts & 5y RFS rate (\%) & P-value & & & P-value & H.R. & $95 \% \mathrm{CL}$ \\
\hline \multirow[t]{2}{*}{ Age } & $<70$ (yrs.) & 122 & 75 & 0.508 & & & & & \\
\hline & $\geq 70$ & 102 & 70 & & & & & & \\
\hline \multirow[t]{2}{*}{ Prostate volume } & $<25(\mathrm{~mL})$ & 138 & 72 & 0.503 & & & & & \\
\hline & $\geq 25$ & 86 & 75 & & & & & & \\
\hline \multirow[t]{3}{*}{ Risk group } & Low & 54 & 87 & $<0.001$ & & & & & \\
\hline & Intermediate & 111 & 78 & & & & & & \\
\hline & High & 59 & 51 & & & & & & \\
\hline \multirow[t]{2}{*}{ T-stage } & $\mathrm{T} 1$ & 117 & 81 & 0.003 & & & 0.04 & 0.59 & $0.36-0.98$ \\
\hline & $\mathrm{T} 2$ & 107 & 64 & & & & & & \\
\hline \multirow[t]{4}{*}{ Gleason score } & $\leq 6$ & 69 & 82 & 0.003 & Ref. & $\leq 6$ & Ref. & & \\
\hline & $3+4$ & 79 & 82 & & 0.109 & 7 & 0.092 & 1.69 & $0.92-3.25$ \\
\hline & $4+3$ & 26 & 58 & & 0.004 & & & & \\
\hline & $\geq 8$ & 50 & 55 & & $<0.001$ & $\geq 8$ & 0.002 & 3 & $1.51-6.12$ \\
\hline \multirow[t]{2}{*}{ Pretreatment PSA } & $<10(\mathrm{ng} / \mathrm{mL})$ & 154 & 79 & $<0.001$ & & & 0.022 & 0.56 & $0.35-0.92$ \\
\hline & $\geq 10$ & 70 & 58 & & & & & & \\
\hline \multirow[t]{2}{*}{ Nadir PSA } & $<0.1(\mathrm{ng} / \mathrm{mL})$ & 120 & 81 & $<0.001$ & & & $<0.001$ & 0.26 & $0.16-0.43$ \\
\hline & $\geq 0.1$ & 104 & 63 & & & & & & \\
\hline \multirow[t]{2}{*}{$\%$ of positive core } & $<40$ & 176 & 74 & 0.553 & & & & & \\
\hline & $\geq 40$ & 48 & 67 & & & & & & \\
\hline \multirow[t]{2}{*}{ ADT before HIFU } & $<3 \mathrm{M}$ & 165 & 74 & 0.422 & & & & & \\
\hline & $\geq 3 \mathrm{M}$ & 59 & 70 & & & & & & \\
\hline \multirow[t]{2}{*}{ HIFU device } & Sonablate 500 & 59 & 65 & 0.049 & & & 0.014 & 1.85 & $1.14-2.97$ \\
\hline & version 4 & 165 & 76 & & & & & & \\
\hline
\end{tabular}

RFS: recurrence-free survival, ADT: androgen deprivation therapy.

Table 5. Kaplan-Meier statistical analyses of factors affecting recurrence-free survival on 111 intermediate-risk patients with first HIFU, and 31 patients with second HIFU.

\begin{tabular}{|c|c|c|c|c|c|c|c|c|}
\hline \multirow[b]{2}{*}{ Variables } & & \multirow[b]{2}{*}{ No. pts. } & \multicolumn{3}{|c|}{ Intermediate 111 pts. } & \multicolumn{3}{|c|}{31 pts. with second-HIFU } \\
\hline & & & $5 y-R F S$ rate (\%) & P-value & & No. pts. & $5 y-R F S$ rate $(\%)$ & P-value \\
\hline \multirow[t]{2}{*}{ T-stage } & $\mathrm{T} 1$ & 57 & 87 & 0.022 & & 15 & 63 & 0.766 \\
\hline & $\mathrm{T} 2$ & 54 & 68 & & & 16 & 65 & \\
\hline \multirow[t]{3}{*}{ Gleason score } & $\leq 3+4$ & 88 & 81 & 0.314 & $\leq 6$ & 9 & 100 & 0.228 \\
\hline & $\geq 4+3$ & 23 & 66 & & 7 & 14 & 63 & \\
\hline & & & & & $\geq 8$ & 8 & 29 & \\
\hline Pretreatment PSA & $<10$ & 67 & 85 & 0.066 & & 19 & 58 & 0.314 \\
\hline$(\mathrm{ng} / \mathrm{mL})$ & $\geq 10$ & 44 & 68 & & & 12 & 79 & \\
\hline Nadir PSA & $<0.1$ & 55 & 90 & 0.002 & & 9 & 100 & 0.018 \\
\hline$(\mathrm{ng} / \mathrm{mL})$ & $\geq 0.1$ & 56 & 64 & & & 22 & 48 & \\
\hline \multirow[t]{2}{*}{ ADT before HIFU } & --- & 88 & 78 & 0.219 & & & & \\
\hline & $\geq 3 \mathrm{M}$ & 23 & 77 & & & & & \\
\hline \multirow[t]{2}{*}{ HIFU device } & Sonablate 500 & 27 & 77 & 0.139 & & 12 & 58 & 0.751 \\
\hline & Version 4 & 84 & 78 & & & 19 & 64 & \\
\hline
\end{tabular}

RFS: recurrence-free survival, ADT: androgen deprivation therapy. 
death due to prostate cancer, we have proven the favorable prognosis of HIFU therapy as same as other reports [19] [20] [21]. And in our risk groups, there was a significant difference between each group. These RFS rates are equal or superior to the long-term outcomes $(49 \%-61 \%$ at 10 -year BDFS in all cases, and $74 \%-88 \%$ in low-risk, $62 \%-83 \%$ in intermediate-risk and $47 \%-68 \%$ in high-risk patients at 5-year BDFS) of the articles [19] [20] [21], which included multiple HIFU sessions, as did our study. Although we were able to achieve a good outcome (RFS rate; over 90\%) in low-risk patients, the outcomes of intermediate and high-risk patients were lower than the reported outcomes of radiotherapy [5] [6] and prostatectomy [3] [22].

In histological examination, we set the prostate biopsy at 6 month after HIFU. Although the negative biopsy rate was $96 \%$ (208/216) at 6month after HIFU, the total negative rate was $88 \%(190 / 216)$, including 18 additional positive patients, who were examined in the follow-up periods. This negative biopsy rate is equal or superior to the rate of some articles (83\% - 87\%) [14] [16] and current review articles (30\% - 95\%) [23] [24]. The histological examinations should be compared at the same time, because these positive rates might vary depending on the multiple follow-up periods.

On the 77 patients who recurred after first-time HIFU, 31 patients chose to receive a second HIFU therapy. Most other patients wanted ADT or radiotherapy. All patients in this study had not chosen an invasive treatment from the start. Of the 31 patients with a second HIFU, 22 cases were followed without recurrence, and 9 cases (1 low, 2 intermediate and 6 high-risk groups) subsequently failed the PSA test, and one high-risk case had a positive biopsy after the second-time HIFU. We used the ASTRO definition and histological results as a basis for judgment for recurrence for this study. Recently, Blana et al. have proposed the Stuttgart definition for the assessment of HIFU [25]. However, our investigations of RFS include the cases with a second HIFU, whereas by the Stuttgart definition, cases with a second HIFU procedure are judged as a clinical failure.

From patient outcomes of second-time HIFU, we believe that the cases in the low and intermediate-risk group did not receive sufficient sonication in their first HIFU treatment, because over half of these patients were successful after the second HIFU. Also, all patients with a second HIFU in the low and intermediate risk group had negative specimens. One particular benefit of HIFU therapy is the ability to repeat the procedure, whereas radiotherapy and prostatectomy therapies are generally not repeatable.

Second-time HIFU is an effective treatment in patients with low-risk. But the outcomes of intermediate-risk patients were less successful, and the high-risk patient's outcomes were poor despite the additional HIFU treatment. These outcome patterns by risk-groups concur with other recent reports [26] [27] [28]. Although most of patients with ADT after recurrence following first HIFU were in the groups of intermediate and high-risk, the 5-year RFS rate was better than that of second-time HIFU. On the other hand, some patients with ADT died of 
another disease or lost follow-up, and 8 recurrent patients with second-time HIFU are alive and well. From the prognosis of recurrence cases, we think that the repeat HIFU was effective, or patients with second-time HIFU had better strength.

To reveal the outcome predictors of RFS, the Kaplan-Meier and multivariate analyses were examined on the results of the first HIFU treatment (Table 4). According these analyses, the significant predictors were T-stage, Gleason score $(\leq 3+4$ vs $\geq 4+3$ ), pretreatment PSA, nadir PSA and HIFU device. Uchida, et al. [21] gave a similar report without ADT before HIFU using these analyses. Uchida's clinical outcomes have improved due to mechanical and technological advancements of the HIFU device. In our analysis, the outcomes using the new HIFU system were better than the older ones, and ADT before HIFU did not have a predictive effect. In a multicenter study [29] of a large patient population (including our outcomes) with localized prostate cancer treated using the Sonablate 500 device, variables shown as significant prognostic parameters by multivariate analyses were pretreatment PSA, clinical stage and neoadjuvant ADT (within 3 months). Short-term ADT before HIFU improved the 3-year disease-free survival rate of patients with intermediate and high-risk non-metastatic prostate cancer. This discrepancy in ADT outcome between the long-term study and our results may be due to the difference in the number of patients, the proportion of intermediate-risk with $4+3$ of Gleason score, number of high-risk patients $(66 \%)$ with $\mathrm{ADT}$ and the difference of ADT periods $(<$ for 3 vs $\geq 3$ months). We chose ADT before HIFU for patients who had large volume prostate or would be expected to have a poor effect by HIFU therapy. Therefore, high-risk patients accounted for over half of the patients with ADT. If we had done this study as a randomized study, patients with ADT before HIFU would have improved outcomes.

To improve the RFS of these HIFU therapies, we studied the statistical analysis of 111 intermediate-risk patients who were the largest group and had insufficient outcomes compared to the low-risk group. From this analysis, T-stage and nadir PSA were important predictive factors. There was a clear difference between $\leq 3+4$ and $\geq 4+3$ of Gleason score on 5-year RFS rates, however there was no significant difference by the statistical analysis. If there are number of $\leq 3+$ 4 and $\geq 4+3$ Gleason score patients, we would expect a significantly difference between the groups, similar to the T-stage analysis.

According to our 13-year experience of 224 patients with clinical stage T1 or T2 prostate cancer, HIFU is an effective treatment in patients with low-risk and intermediate-risk with T1-stage. But even with ADT before HIFU, we think HIFU therapy is not suitable for the patients with high-risk and $\geq 8$ of Gleason score. Our experience indicated that T-stage, Gleason score, pretreatment PSA and nadir PSA are effective predictors for determination of HIFU therapy outcomes. In particular, nadir PSA was found to be the most important for RFS after HIFU therapy as noted in another large volume report [26]. Therefore, HIFU therapy of localized prostate cancer should be selected for low and intermediate-risk pa- 
tients with clinical T1-stage, and patients with PSA $<10 \mathrm{ng} / \mathrm{ml}$ and $\leq 3+4$ of Gleason score. For intermediate-risk patients with stage T2 and high-risk patients, sufficient HIFU sonication and ADT before HIFU are necessary to improve results. As discussed in some reports [20] [21], the outcomes of these higher-risk patients would be improved by the mechanical and technological improvement of HIFU instrument.

\section{Conclusion}

Prognosis of HIFU was good for patients with localized prostate cancer and for patients with second-HIFU by recurrence after a first-HIFU. The low and intermediate-risk patients with T1-stage, PSA $<10 \mathrm{ng} / \mathrm{ml}$ and Gleason score $\leq 3+4$ are suitable indications for HIFU. Effective predictors for outcomes were risk-group, T-stage, Gleason score, pretreatment PSA and nadir PSA.

\section{References}

[1] Namiki, S., Ishidoya, S., Ito, A., Kawamura, S., Tochigi, T., Saito, S. and Arai, Y. (2009) Quality of Life after Radical Prostatectomy in Japanese Men: A 5-Year Follow up Study. International Journal of Urology, 16, 75-81. http://onlinelibrary.wiley.com/doi/10.1111/j.1442-2042.2008.02197.x/abstract https://doi.org/10.1111/j.1442-2042.2008.02197.x

[2] Verze, P., Scuzzarella, S., Martina, G.R., Giummelli, P., Cantoni, F. and Mirone, V. (2013) Long-Term Oncological and Functional Results of Extraperitoneal Laparoscopic Radical Prostatectomy: One Surgical Team's Experience on 1,600 Consecutive Cases. World Journal of Urology, 31, 529-534.

http://link.springer.com/article/10.1007\%2Fs00345-013-1052-0 https://doi.org/10.1007/s00345-013-1052-0

[3] Busch, J., Stephan, C., Herold, A., Erber, B., Kempkensteffen, C., Hinz, S., Lein, M., Weikert, S., Miller, K. and Magheli, A. (2012) Long-Term Oncological and Continence Outcomes after Laparoscopic Radical Prostatectomy: A Single-Centre Experience. BJU International, 110, E985-990.

http://onlinelibrary.wiley.com/doi/10.1111/j.1464-410X.2012.11279.x/abstract https://doi.org/10.1111/j.1464-410X.2012.11279.x

[4] Odrazka, K., Dolezel, M., Vanasek, J., Vaculikova, M., Zouhar, M., Sefrova, J.l., Paluska, P., Vosmik, M., Kohlova, T., Kolarova, I., Navratil, P., Brodak, M., Prosvic, P. and Hoffmann, P. (2010) Late Toxicity after Conformal and Intensity-Modulated Radiation Therapy for Prostate Cancer: Impact of Previous Surgery for Benign Prostatic Hyperplasia. International Journal of Urology, 17, 784-790. http://onlinelibrary.wiley.com/doi/10.1111/j.1442-2042.2010.02592.x/abstract https://doi.org/10.1111/j.1442-2042.2010.02592.x

[5] Vora, A.V., Wong, W.W., Schild, S.E., Ezzell, G.A., Andrews, P.E., Ferrigni, R.G. and Swanson, S.K. (2013) Outcome and Toxicity for Patients Treated with Intensity Modulated Radiation Therapy for Localized Prostate Cancer. The Journal of Urology, 190, 521-526.

http://www.jurology.com/article/S0022-5347(13)00279-6/abstract https://doi.org/10.1016/j.juro.2013.02.012

[6] Zelefsky, M.J., Kuban, D.A., Levy, L.B., Potters, L., Beyer, D.C., Blasko, J.C., Moran, B.J., Ciezki, J.P., Zietman, A.L., Pisansky, T.M., Elshaikh, M. and Horwits, E.M. (2007) Multi-Institutional Analysis of Long-Term Outcome for stageT1-T2 Prostate 
Cancer Treated with Permanent Seed Implantation. International Journal of Radiation Oncology, Biology, Physics, 67, 327-333.

http://www.redjournal.org/article/S0360-3016(06)02817-3/abstract https://doi.org/10.1016/j.ijrobp.2006.08.056

[7] Cohen, J.K., Miller, R.J., Ahmed, S., and Baust, J. (2008) Ten-Year Biochemical Disease Control for Patients with Prostate Cancer Treated with Cryosurgery as Primary Therapy. Urology, 71, 515-518.

http://www.goldjournal.net/article/S0090-4295(07)02193-0/abstract https://doi.org/10.1016/j.urology.2007.09.059

[8] Maderbacher, S., Pedevilla, M., Vinger, L., Susani, M. and Marberger, M. (1955) Effect of High-Intensity Focused Ultrasound on Human Prostate Cancer in Vivo. Cancer Research, 55, 3346-3351. http://cancerres.aacrjournals.org/content/55/15/3346.long

[9] Gelet, A., Chapelon, J.Y., Bouvier, R., Rouviere, O., Lasne, Y., Lyonnet, D. and Dubernard, J.M. (2000) Transrectal High-Intensity Focused Ultrasound: Minimally Invasive Therapy of Localized Prostate Cancer. Journal of Endourology, 14, 519-528. https://www.ncbi.nlm.nih.gov/pubmed/10954310 https://doi.org/10.1089/end.2000.14.519

[10] Inoue, Y., Goto, K., Hayashi, T. and Hayashi, M. (2011) Transrectal High-Intesity Focused Ultrasound for Treatment of Localized Prostate Cancer. International Journal of Urology, 18, 358-362.

http://onlinelibrary.wiley.com/doi/10.1111/j.1442-2042.2011.02739.x/abstract https://doi.org/10.1111/j.1442-2042.2011.02739.x

[11] Hayashi, M., Oka, K. and Inoue, K. (2015) Long-Term Outcomes of Transrectal High-Intensity Focused Ultrasound for Localized Prostate Cancer. Japanese Journal of Endourology, 28, 322-330. https://www.jstage.jst.go.jp/article/jsejje/28/2/28 322/ article

[12] D’Amico, A.V., Whittington, R., Malkowicz, S.B., Schults, D., Blank, K., Broderick, G.A., Tomaszewski, J.E., Renshaw, A.A., Kaplan, I., Beard, C.J. and Wein, A. (1998) Biochemical Outcome after Radical Prostatectomy, External Beam Radiation Therapy, or Interstitial Radiation Therapy for Clinically Localized Prostate Cancer. The Journal of the American Medical, 280, 969-974. http://jamanetwork.com/journals/jama/fullarticle/187980 https://doi.org/10.1001/jama.280.11.969

[13] Roach, M., Hanks, G., Thames, H., Schellhammer, P., Shipley, W.U., Sokol, G.H. and Sandler, H. (2006) Defining Biochemical Failure Following Radiotherapy with or without Hormonal Therapy in Men with Clinically Localized Prostate Cancer: Recommendations of the RTOG-ASTRO Phoenix Conference. International Journal of Radiation Oncology, Biology, Physics, 65, 965-974.

http://www.redjournal.org/article/S0360-3016(06)00663-8/abstract

https://doi.org/10.1016/j.ijrobp.2006.04.029

[14] Thuroff, S., Chaussy, C., Vallancien, G., Wieland, W., Kiel, H.J., Duc, A.L., Desgrandchamps, F., Rosette, J.D.L. and Gelet, A. (2003) High-Intensity Focused Ultrasound and Localized Prostate Cancer: Efficacy Results from the European Multicentric Study. Journal of Endourology, 17, 673-677.

http://online.liebertpub.com/doi/abs/10.1089/089277903322518699 https://doi.org/10.1089/089277903322518699

[15] Blana, A., Walter, B., Rogenhofer, S. and Wieland, W. (2004) High-Intensity Focused Ultrasound for the Treatment of Localized Prostate Cancer: 5-Year Experience. Urology, 63, 297-300. 
http://www.goldjournal.net/article/S0090-4295(03)01008-2/abstract https://doi.org/10.1016/j.urology.2003.09.020

[16] Uchida, T., Shoji, S., Nakano, M., Hongo, S., Nitta, M., Murota, A. and Nagata, Y. (2009) Transrectal High-Intensity Focused Ultrasound for the Treatment of Localized Prostate Cancer; Eight-Year Experience. International Journal of Urology, 16, 881-886.

http://onlinelibrary.wiley.com/doi/10.1111/j.1442-2042.2009.02389.x/abstract https://doi.org/10.1111/j.1442-2042.2009.02389.x

[17] Baco, E., Gelet, A., Crouzet, S., Rud, E., Rouviere, O., Tonoli-Catez, H., Berge, V., Chapelon, J.Y. and Eggesbo, H.B. (2014) Hemi Salvage High-Intensity Focused Ultrasound (HIFU) in Unilaterall Radiorecuuent Prostate Cancer: A Prospective Two-Centre Study. BJU International, 114, 532-540.

http://onlinelibrary.wiley.com/doi/10.1111/bju.12545/abstract https://doi.org/10.1111/bju.12545

[18] Shoji, S., Mouraviev, V. and Scionti, S. (2016) High-Intensity Focused Ultrasound Treatment. Handbook of Focal Therapy for Prostate and Renal Cancer, 241-254.

[19] Ganzer, R., Fritsche, H.M., Brandtner, A., Brundl, J., Koch, D., Wieland, W.F. and Blana, A. (2013) Fourteen-Year Oncological and Functional Outcomes of High-Intensity Focused Ultrasound in Localized Prostate Cancer. BJU International, 112, 322-329.

http://onlinelibrary.wiley.com/doi/10.1111/j.1464-410X.2012.11715.x/abstract https://doi.org/10.1111/j.1464-410X.2012.11715.X

[20] Crouzet, S., Chapelon, J.Y., Rouviere, O., Mege-Lechevallier, F., Colombel, M., Tonoli-Catez, H., Martin, X. and Gelet, A. (2014) Whole-Gland Ablation of Localized Prostate Cancer with High-Intensity Focused Ultrasound Oncologic Outcomes and Morbidity in 1002 Patients. European Urology, 65, 907-914. http://www.europeanurology.com/article/S0302-2838(13)00424-7/abstract https://doi.org/10.1016/j.eururo.2013.04.039

[21] Uchida, T., Tomonaga, T., Kim, H., Nakano, M., Shoji, S., Nagata, Y. and Terachi, T. (2015) Improved Outcomes with Advancements in High Intensity Focused Ultrasound Devices for the Treatment of Localized Prostate Cancer. The Journal of Urology, 193, 103-110.

http://www.jurology.com/article/S0022-5347(14)04047-6/abstract https://doi.org/10.1016/j.juro.2014.07.096

[22] Menon, M., Bhandari, M., Gupta, N., Lane, Z., Peabody, J.O., Rogers, C.G., Sammon, J., Siddiqui, S.A. and Diaz, M. (2010) Biochemical Recurrence Following Robot-Assisted Radical Prostatectomy: Analysis of 1384 Patients with A Median 5-Year Follow-Up. European Urology, 838-846.

http://eu-acme.org/europeanurology/upload articles/Sammon.pdf https://doi.org/10.1016/j.eururo.2010.09.010

[23] Lukka, H., Waldron., T., Chin, J., Mayhew, L., Warde, P., Winquist, E., Rodrigues, G. and Shayegan, B. (2011) High-Intensity Focused Ultrasound for Prostate Cancer: A Systematic Review. Clinical Oncology, 23, 117-127. http://www.clinicaloncologyonline.net/article/S0936-6555(10)00372-9/pdf https://doi.org/10.1016/j.clon.2010.09.002

[24] Uchida, T., Nakano, M., Hongo, S., Shoji, S., Nagata, Y., Satoh, T., Baba, S., Usui, Y. and Terachi, T. (2012) High-Intensity Focused Ultrasound Therapy for Prostate Cancer. International Journal of Urology, 19, 187-201.

http://onlinelibrary.wiley.com/doi/10.1111/j.1442-2042.2011.02936.x/abstract https://doi.org/10.1111/j.1442-2042.2011.02936.x 
[25] Blana, A., Brown, S.C.W., Chaussy, C., Conti, G.N., Eastham, J.A., Ganzer, R., Murat, F.J., Pasticier, G., Rebillard, X., Rewcastle, J.C., Robertson, C.N., Thuroff, S. and Ward, J.F. (2009) High-Intensity Focused Ultrasound for Prostate Cancer: Comparative Definitions of Biochemical Failure. BJU International, 104, 1058-1062. http://onlinelibrary.wiley.com/doi/10.1111/j.1464-410X.2009.08518.x/abstract https://doi.org/10.1111/j.1464-410X.2009.08518.x

[26] Mearini, L., D’Urso, L., Collura, D., Zucchi, A., Costantini, E., Formiconi, A., Bini, V., Muto, G. and Porena, M. (2008) Visually Directed Transrectal High Intensity Focused Ultrasound for the Treatment of Prostate Cancer : A Preliminary Report on the Italian Experience. The Journal of Urology, 181, 105-112.

http://www.jurology.com/article/S0022-5347(08)02444-0/abstract https://doi.org/10.1016/j.juro.2008.09.024

[27] Thuroff, S. and Chaussy, C. (2013) Evolution and Outcomes of $3 \mathrm{MHz}$ High Intensity Focused Ultrasound Therapy for Localized Prostate Cancer During 15 Years. The Journal of Urology, 190, 702-710.

http://www.jurology.com/article/S0022-5347(13)00277-2/abstract https://doi.org/10.1016/j.juro.2013.02.010

[28] Crouzet, S., Rebillard, X., Chevallir, D., Rischmann, P., Pasticier, G., Garcia, G., Rouvier, O., Chapelon, J.Y. and Gelet, A. (2010) Multicentric Oncologic Outcomes of High-Intensity Focused Ultrasound for Localized Prostate Cancer in 803 Patients. European Urology, 58, 559-566.

http://www.europeanurology.com/article/S0302-2838(10)00596-8/pdf https://doi.org/10.1016/j.eururo.2010.06.037

[29] Sumitomo, M., Hayashi, M., Watanabe, T., Tsugawa, M., Noma, H., Yamaguchi, A., Nagakura, K., Hayakawa, M. and Uchida, T. (2008) Efficacy of Short-Term Androgen Deprivation with High-Intensity Focused Ultrasound in the Treatment of Prostate Cancer in Japan. Urology, 72, 1335-1340. http://www.goldjournal.net/article/S0090-4295(07)02613-1/abstract https://doi.org/10.1016/j.urology.2007.12.041

\section{Abbreviations \& Acronyms}

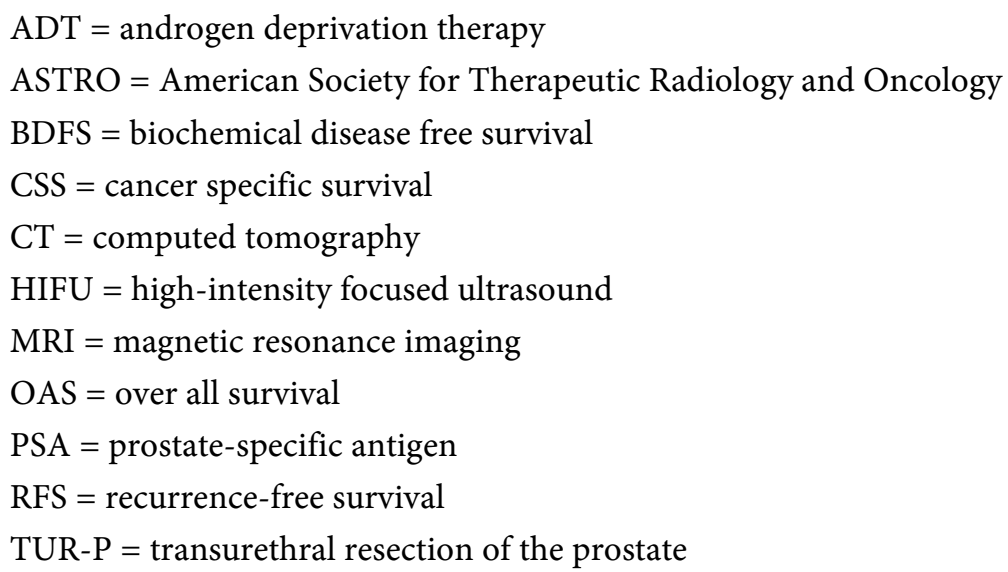


Submit or recommend next manuscript to SCIRP and we will provide best service for you:

Accepting pre-submission inquiries through Email, Facebook, LinkedIn, Twitter, etc. A wide selection of journals (inclusive of 9 subjects, more than 200 journals)

Providing 24-hour high-quality service

User-friendly online submission system

Fair and swift peer-review system

Efficient typesetting and proofreading procedure

Display of the result of downloads and visits, as well as the number of cited articles Maximum dissemination of your research work

Submit your manuscript at: http://papersubmission.scirp.org/

Or contact oju@scirp.org 